\title{
Survival and associated risk factors in patients with diabetes and amputations caused by infectious foot gangrene
}

\author{
Yu-Yao Huang ${ }^{1,2^{*}}$, Cheng-Wei Lin ${ }^{1}$, Hui-Mei Yang ${ }^{1}$, Shih-Yuan Hung ${ }^{1}$ and I-Wen Chen
}

\begin{abstract}
Background: Infectious gangrene of the foot is a serious complication of diabetes that usually leads to a certain level of lower-extremity amputation (LEA). Nevertheless, the long-term survival and factors associated with mortality in such patients have yet to be elucidated.

Methods: A total of 157 patients with type 2 diabetes who received treatment for infectious foot gangrene at a major diabetic foot center in Taiwan from 2002 to 2009 were enrolled, of whom 90 had major LEAs (above the ankle) and 67 had minor LEAs (below the ankle). Clinical data during treatment were used for the analysis of survival and LEA, and survival was tracked after treatment until December 2012.

Results: Of the 157 patients, 109 died, with a median survival time of 3.12 years and 5-year survival rate of $40 \%$. Age [hazard ratio 1.04 (95\% confidence interval 1.01-1.06)], and major LEA [1.80 (1.05-3.09)] were independent factors associated with mortality. Patients with minor LEAs had a better median survival than those with major LEAs (5.5 and 1. 9 years, respectively, $P<0.01)$. An abnormal ankle-brachial index was an independent risk factor [odds ratio $3.12(95 \% \mathrm{Cl}$ 1.18-8.24)] for a poor outcome (major LEA) after adjusting for age, smoking status, hypertension, major adverse cardiac events, and renal function.

Conclusions: Efforts to limit amputations below the ankle resulted in better survival of patients with infectious foot gangrene. An abnormal ankle-brachial index may guide physicians to make appropriate decisions with regards to the amputation level.
\end{abstract}

Keywords: Diabetes, Infectious foot gangrene, Survival, Lower-extremity amputation

\section{Background}

Foot gangrene, defined as dead tissue in the foot resulting from inadequate blood flow supply, is one of the manifestations of critical limb ischemia [1]. It can be caused by obstructed peripheral circulation or bacterial infections [2]. Foot ulcers in patients with diabetes are at an increased risk of foot gangrene, mainly due to peripheral arterial disease (PAD) [3] and foot infections [4]. Foot gangrene can be classified into two types: (1) dry gangrene with ischemic tissue but no infection, and (2) wet gangrene with

\footnotetext{
*Correspondence: yyh@cgmh.org.tw

'Division of Endocrinology and Metabolism, Department of Internal

Medicine, Chang Gung Memorial Hospital, Chang Gung University, 5, Fuxing St., Guishan Dist, Taoyuan City 333, Taiwan

2Department of Medical Nutrition Therapy, Chang Gung Memorial Hospital,

Chang Gung University, 5, Fuxing St., Guishan Dist, Taoyuan City 333, Taiwan
}

both infectious and necrotic tissue [2]. Infectious foot gangrene (wet gangrene) is both a limb- and lifethreatening disease. Proper medical treatment with antibiotics and wound dressing may not be effective without timely surgery to remove the necrotic and infectious tissue [2].

Previous reports have shown that patients with diabetes-related amputations have a high risk of mortality, with a 5 -year survival rate of $40-48 \%$ regardless of the etiology of the amputation [5-7]. The risk factors associated with survival have been investigated in patients with diabetic foot ulcers $[8,9]$ but rarely in diabetic amputees [7]. Survival analysis is also lacking in patients with diabetes and infectious foot gangrene who need more medical attention for both critical limb ischemia and limb-threatening infections [10]. Therefore, the aim 
of this study was to investigate the survival outcomes of patients with diabetes and amputations due to infectious foot gangrene and the factors associated with the prognosis.

\section{Methods}

\section{Patients and hospital care}

A total of 157 patients with type 2 diabetes and infectious foot gangrene who were admitted to the diabetic foot care center of Chang Gung Memorial Hospital in Taiwan from 2002 to 2009 were enrolled. This study was approved by the Institutional Review Board of Chang Gung Memorial Hospital (no. 104-1401B). All of the patients received multidisciplinary care including glycemic control, antibiotic treatment and wound dressing. Surgical interventions to remove necrotic tissue or limbs were determined according to the consensus of a team of physicians taking into account the risk of mortality due to co-morbidities and clinical status or an obviously poor likelihood of preserving the foot (due to large tissue defects, uncontrolled infections or severe artery occlusion with no possibility of revascularization) $[11,12]$.

All of the enrolled patients received some degree of gangrene tissue removal, including 90 with major lowerextremity amputation (LEAs) (above the ankle) and 67 with minor LEAs (including digital amputation or tarsalmetatarsal amputation but not the ankle area).

\section{Data collection}

Survival time was calculated from the discharge date to December 31, 2012, or death. Information of death was obtained from the National Health Insurance database.

Clinical data were collected during the admission for foot gangrene treatment. Age, duration of diabetes and HbA1c were recorded as continuous variables. Gender, smoking status, underlying co-morbidities (hypertension, major adverse cardiac events (MACEs), and renal status), ankle-brachial index (ABI) and amputation level were recorded as categorical variables. Smokers were defined as currently smoking with at least one cigarette per day, and renal status was defined according to the National Kidney Disease Outcomes Quality Initiative (NKDOQI) guidelines as follows: normal renal function with an estimated glomerular filtration rate (eGFR) calculated according to the modification of diet in renal disease equation of $\geq 60 \mathrm{ml} / \mathrm{min}$; moderate chronic kidney disease (CKD) with an eGFR $<60 \mathrm{ml} / \mathrm{min}$ but not requiring dialysis treatment; and dialysis status as the continuous need for renal replacement therapy. ABI was calculated by measuring the ratio of the blood pressure of the lower leg to the blood pressure in the arm according to the 2011 American Heart Association guidelines for peripheral arterial disease [13], and an abnormal ABI was defined as either $\leq 0.9$ or $>1.4$.

\section{Statistics}

Kaplan-Meier method was used to estimate the survival probability for differing survival times (time to event). Each variable was entered into a multivariate Cox regression model to identify the independent risk factors associated with mortality. Differences in survival and clinical data were calculated between the minor and major LEA groups using the Kaplan-Meier method and log rank test for survival, the Student's $t$ test for continuous variables, and Pearson's chi-square test for categorical variables. In addition, multivariate logistic regression analysis was performed including age, smoking status, hypertension, MACEs, renal function and PAD to identify the independent risk factors predicting the outcomes of the patients with major LEAs.

All statistical analyses were performed using the Statistical Package for the Social Sciences (SPSS for Windows, version 19.0, IBM Corp., Armonk, NY). Statistical significance was defined as a $P$ value $<0.05$.

\section{Results}

\section{Demographic data}

The mean age of the enrolled patients was 66.8 years, and $63.1 \%$ of the patients were male (Table 1 ). Overall, $70.7 \%$ of the patients had underlying hypertension, $33.1 \%$ had MACEs, and 25.5\% were undergoing chronic dialysis for end-stage renal disease (Table 1). PAD was noted in $60 \%$ of the patients, with 11 patients having an $\mathrm{ABI}>1.4$ and 93 an $\mathrm{ABI} \leq 0.9$.

\section{Survival analysis}

Of the 157 enrolled patients, 109 died during a mean of 3.7 years observation period (range: $0-10.5$ years). The 5 -year survival rate was $40 \%$ with a median survival time of 3.12 years and a crude mortality rate of 187.64 per 1000 patient-years.

In multivariate Cox regression analysis with the variables listed in Table 1, age [adjusted hazard ratio (aHR) 1.04 (95\% confidence interval (CI) 1.01-1.06)] and major LEA [aHR 1.80 (95\% CI 1.05-3.09)] were independent risk factors associated with long-term mortality (Table 1). Although there was no statistical difference in renal function, the patients undergoing dialysis had a 2-fold higher risk of mortality compared to those with normal renal function [aHR 2.09 (95\% CI 0.99-4.41)]. In contrast, the survival curves of the patients with or without CKD were similar (Fig. 1 and Table 1). Figure 1 shows an early separation of survival curves between the patients with minor and major LEAs. Compared to the patients with minor LEAs, those with major LEAs had an $80 \%$ higher risk of mortality. The median survival 
Table 1 Demographics and clinical characteristics of the patients with diabetes and infectious foot gangrene and risk factors for mortality in a Cox proportional hazards model (Total number: 157)

\begin{tabular}{|c|c|c|c|c|}
\hline \multirow[t]{2}{*}{ Characteristic } & \multirow{2}{*}{\multicolumn{2}{|c|}{$\begin{array}{l}\text { Mean (standard deviation) or } \\
\text { Number (\%) }\end{array}$}} & \multicolumn{2}{|l|}{ Multivariate $^{+}$analysis } \\
\hline & & & \multirow{2}{*}{$\begin{array}{l}\text { Mortality HR }(95 \% \mathrm{Cl}) \\
1.04^{*}(1.01-1.06)\end{array}$} & \multirow{2}{*}{$\frac{P \text { value }}{0.01}$} \\
\hline Age (years) & 66.8 & $( \pm 10.8)$ & & \\
\hline Gender & & & & 0.37 \\
\hline Female & 58 & $(36.9 \%)$ & 1 & \\
\hline Male & 99 & $(63.1 \%)$ & $0.79(0.46-1.33)$ & \\
\hline Diabetes duration (years) & 12.8 & $( \pm 8.4)$ & $1.14(0.92-1.43)$ & 0.24 \\
\hline Smoking status & 34 & $(21.7 \%)$ & $1.48(0.73-3.01)$ & 0.28 \\
\hline Hypertension & 111 & $(70.7 \%)$ & $1.06(0.63-1.80)$ & 0.83 \\
\hline Major adverse cardiac events & 52 & $(33.1 \%)$ & $1.48(0.88-2.50)$ & 0.14 \\
\hline Abnormal ABI & 104 & $(66.2 \%)$ & $1.28(0.67-2.42)$ & 0.46 \\
\hline \multicolumn{5}{|l|}{ Renal function } \\
\hline $\begin{array}{l}\text { Normal renal function } \\
(\mathrm{eGFR} \geq 60)\end{array}$ & 58 & $(36.9 \%)$ & 1 & \\
\hline $\begin{array}{l}\text { Chronic kidney disease } \\
\text { (eGFR <60) }\end{array}$ & 59 & $(37.6 \%)$ & $0.87(0.48-1.59)$ & 0.66 \\
\hline Dialysis & 40 & $(25.5 \%)$ & $2.09^{\wedge}(0.99-4.41)$ & 0.05 \\
\hline $\mathrm{HbA1c}(\%)$ & 9.4 & $( \pm 2.7)$ & $1.02(0.92-1.13)$ & 0.71 \\
\hline \multicolumn{5}{|l|}{ Limb amputation status } \\
\hline Minor LEA & 67 & $(42.7 \%)$ & 1 & \\
\hline Major LEA & 90 & $(57.3 \%)$ & $1.80^{*}(1.05-3.09)$ & 0.03 \\
\hline
\end{tabular}

"Significance: $P$ value $<0.05$

^Borderline significance: $P$ value $=0.05$

${ }^{+}$Including continuous variables of age, diabetes duration, and $\mathrm{HbA1c}$; and categorical variables of gender, smoking status, hypertension, major adverse cardiac events, ankle-brachial index, renal function and LEA status

$H R$ hazard ratio, $A B I$ ankle-brachial index, eGFR estimated glomerular filtration rate, $L E A$ lower-extremity amputation

time of the patients with minor LEAs was 5.5 years, compared to 1.9 years for those with major LEAs $(P<$ 0.01) (Table 2).

\section{Comparisons between the minor and major LEA groups}

The patients with major LEAs had obviously abnormal ABI values at treatment ( $80 \%$ vs. $47.8 \%, P<0.01)$, and also relatively higher rates of MACEs and renal dysfunction although without reaching statistical significance. A longer hospital stay has been observed in patients with minor LEAs than those with major LEAs (48.2 vs. 36.9 days, respectively, $P=0.03$ ).

Since LEA status had an impact on survival, we further analyzed the factors predicting the level of LEA (Table 3). After adjusting for clinical data including age, smoking status, hypertension, MACEs, and renal function in multivariate logistic regression analysis, an abnormal ABI value at treatment was an independent factor predicting a major LEA [odds ratio 3.12 (95\% CI 1.18-8.24), $P=0.02$ ].

\section{Discussion}

In this study, the patients with diabetes and infectious foot gangrene related amputees had a 5-year survival rate of $40 \%$ after treatment. This survival rate is not better than other studies on diabetic amputees with various etiologies, ranging from a 5-year survival rate of around $40 \%$ reported by Tseng et al. [5], 44\% by Hambleton et al. [6], $47.7 \%$ by Lavery et al. [7] and $64 \%-84.2 \%$ by Izumi et al. [14]. The mean age of our patients was 66.8 years, which is similar to that in the studies by Lavery et al. and Tseng et al. (64.8 and 66.6 years, respectively) but older than that in Izumi et al.'s study (53.8 years). A more recent study reported a 30\% 5-year survival rate in patients with diabetes and major LEA, which is similar to our subgroup patients with major LEA [15].

In addition to the age factor, another independent factor associated survival is the outcome of major LEA. Major LEAs resulted in a worse survival prospect than minor LEAs, which is consistent with other survival studies on diabetic amputees $[6,7,14]$. This may be due to major LEA-related disabilities such as limited mobility [16], bed-ridden status [17], and higher risk of falls [18]. Furthermore, a major LEA by itself may increase the risk of cardiovascular disease because of behavioral changes, psychosocial stress, and increases in inflammation and insulin resistance [19]. 

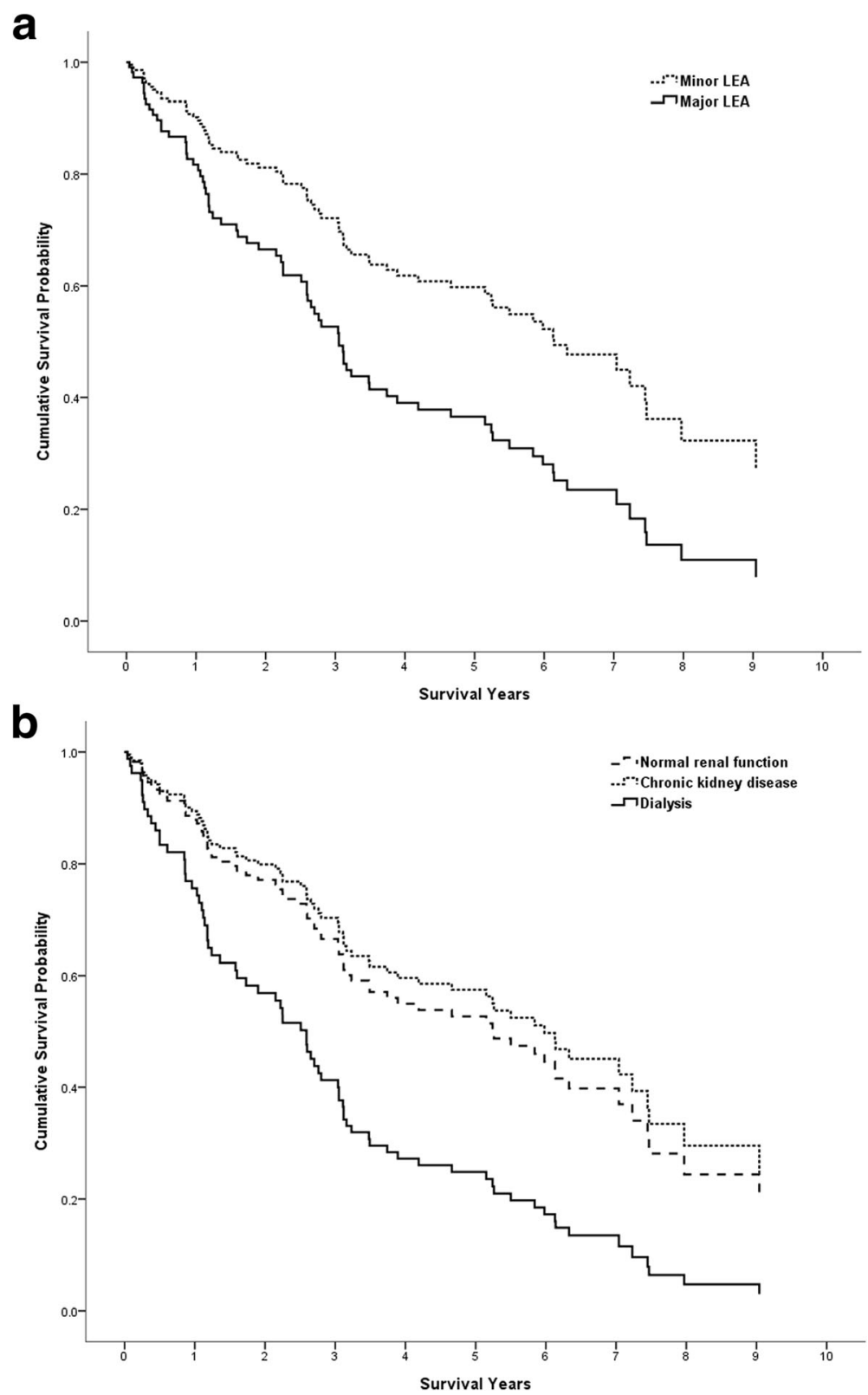

Fig. 1 Adjusted survival curve from a Cox proportional hazard model according to limb amputation status and renal function status. a Compared to the minor LEA group, the adjusted hazard ratio for mortality was $1.80(95 \% \mathrm{Cl} 1.05-3.09, P=0.03)$ for those with major LEAs. $\mathbf{b}$ Compared to the normal renal function group, the adjusted hazard ratio for mortality was 0.87 ( $95 \% \mathrm{Cl} 0.48-1.59, P=0.66)$ for those with CKD and 2.09 ( $95 \% \mathrm{Cl}$ $0.99-4.41, P=0.05)$ for those undergoing dialysis. Covariates included continuous variables of age, diabetes duration, and HbA1c; and categorical variables of hypertension, major adverse cardiac events, renal function, $A B I$ value and limb amputation status

Prompt major LEA for infectious foot gangrene is sometimes suggested by physicians to control foot infection and also to allow for early rehabilitation such as wearing prostheses and ambulation to avoid restricted activity-related disabilities during hospitalization [20]. However, the rate of successful rehabilitation after major LEA is low because of poor motivation and multiple comorbidities, and only around $37 \%$ of patients who undergo a major LEA recover to pre-amputation mobility [21].

The results of this study suggest that even though factors such as age and dialysis status beyond our control, avoiding major LEAs could prolong the survival of patients with diabetes and infectious foot gangrene. However, limb preservation is challenging for those patients because of difficulty in wound 
Table 2 Clinical characteristics of the patients with diabetes and infectious foot gangrene with different LEA status

\begin{tabular}{|c|c|c|c|c|c|}
\hline \multirow[t]{2}{*}{ Characteristic } & \multicolumn{5}{|c|}{ Mean (standard deviation) or Number (\%) } \\
\hline & \multicolumn{2}{|c|}{$\begin{array}{l}\text { Minor LEA } \\
(n=67)\end{array}$} & \multicolumn{2}{|c|}{$\begin{array}{l}\text { Major LEA } \\
(n=90)\end{array}$} & $P$ value \\
\hline Death & \multicolumn{2}{|l|}{38} & \multicolumn{2}{|l|}{48} & \\
\hline Median survival time (years) & \multicolumn{2}{|c|}{5.5 (95\% Cl: 2.58-8.42) } & \multicolumn{2}{|c|}{1.9 (95\% Cl: $1.15-2.65)$} & $<0.01^{*}$ \\
\hline 5-year survival rate & \multicolumn{2}{|l|}{$54 \%$} & \multicolumn{2}{|l|}{$30 \%$} & \\
\hline Age (years) & 65.8 & $( \pm 11.7)$ & 67.6 & $( \pm 10.1)$ & 0.32 \\
\hline \multicolumn{5}{|l|}{ Gender } & \multirow[t]{3}{*}{0.56} \\
\hline Female & 23 & $(34.3 \%)$ & 35 & $(38.9 \%)$ & \\
\hline Male & 44 & $(65.7 \%)$ & 55 & $(61.1 \%)$ & \\
\hline Diabetes duration (years) & 11.9 & $( \pm 8.9)$ & 13.5 & $( \pm 8.1)$ & 0.24 \\
\hline Smoking status & 18 & $(26.9 \%)$ & 16 & $(17.8 \%)$ & 0.17 \\
\hline Hypertension & 44 & $(65.7 \%)$ & 67 & $(74.4 \%)$ & 0.23 \\
\hline Major adverse cardiac events & 17 & $(25.4 \%)$ & 35 & $(38.9 \%)$ & 0.08 \\
\hline Abnormal ABl & 32 & $(47.8 \%)$ & 72 & $(80.0 \%)$ & $<0.01^{*}$ \\
\hline \multicolumn{5}{|l|}{ Renal function } & \multirow[t]{4}{*}{0.09} \\
\hline $\begin{array}{l}\text { Normal renal function } \\
\text { (eGFR } \geq 60 \text { ) }\end{array}$ & 31 & $(46.3 \%)$ & 27 & $(30.0 \%)$ & \\
\hline $\begin{array}{l}\text { Chronic kidney disease } \\
\text { (eGFR <60) }\end{array}$ & 23 & $(34.3 \%)$ & 36 & $(40.0 \%)$ & \\
\hline Dialysis & 13 & $(19.4 \%)$ & 27 & $(30.0 \%)$ & \\
\hline $\mathrm{HbA} 1 \mathrm{c}(\%)$ & 9.7 & $( \pm 2.5)$ & 9.0 & $( \pm 2.9)$ & 0.14 \\
\hline Hospitalization duration (days) & 48.2 & $( \pm 34.7)$ & 36.9 & $( \pm 25.2)$ & $0.03^{*}$ \\
\hline
\end{tabular}

"Significance: $P$ value $<0.05$

+Including continuous variables of age and diabetes duration; and categorical variables of gender, smoking status, hypertension, major adverse cardiac events, ankle-brachial index, and renal function

$L E A$ lower-extremity amputation, $A B I$ ankle-brachial index, eGFR estimated glomerular filtration rate

healing, severe comorbidities, and the high risk of progressive sepsis [22]. Furthermore, the aggressive limb preservation treatments may include revascularization procedures, advanced wound dressing, offloading, and meticulous medical cares [23]. That also explains longer hospital stays in patients with minor
LEA. It is also troubling to directly perform a major LEA because of the resistance of patients and their family [24].

In this and our previous study, we showed that the $A B I$ value could be used as a predictor for the outcome of minor or major LEAs [25]. However, it could not

Table 3 Multivariate logistic regression analysis of risk factors to predict major LEA in the patients with infectious foot gangrene

\begin{tabular}{lllll}
\hline Factors $^{+}$ & Interpretation & Odds ratio & $95 \%$ confidence interval & $P$ value \\
\hline Abnormal ABI & Yes vs. No & $3.12^{*}$ & $1.18-8.24$ & 0.02 \\
Age & Every 1 year increment & 0.97 & $0.93-1.02$ & 0.21 \\
Diabetes duration & Every 1 year increment & 0.99 & $0.94-1.04$ & $0.19-1.53$ \\
Smoking status & Yes vs. No & 0.54 & $0.53-3.10$ & 0.25 \\
Hypertension & Yes vs. No & 1.28 & $0.45-2.80$ & 0.59 \\
MACE history & Yes vs. No & 1.13 & $0.74-4.46$ & 0.80 \\
CKD (eGFR $<60)$ & vs. normal renal function (eGFR $\geq 60)$ & 1.81 & $0.71-8.85$ & 0.20 \\
Dialysis & vs. normal renal function (eGFR $\geq 60)$ & 2.51 & $0.81-1.13$ & 0.58 \\
HbA1c & Every 1\% increment & 0.95 &
\end{tabular}

"Significance: $P$ value $<0.05$

+Including the continuous variable of age, diabetes duration and $\mathrm{HbA} 1 \mathrm{c}$; and categorical variables of smoking status, hypertension, major adverse cardiac events, ankle-brachial index, and renal function

LEA lower-extremity amputation, $A B I$ ankle-brachial index, MACE major adverse cardiac event, CKD chronic kidney disease, eGFR estimated glomerular filtration rate 
predict survival prospect in this population. To date, no study has investigated the influence of the $\mathrm{ABI}$ on survival rate in diabetic amputees. However, ABI value has been reported to be an independent risk factor for survival in patients with diabetes and foot ulcers regardless of the LEA status $[8,9]$. The ABI has also been reported to be a predictor of MACEs because PAD is thought to be a manifestation of systemic atherosclerosis rather than only localized disease [26, 27]. This suggests patients with diabetes and infectious foot gangrene are at risk of systemic atherosclerosis in addition to limb PAD. Accordingly, for the patients with foot gangrene and a normal ABI, it is more beneficial to preserve more distal limbs by aggressive treatment, because if the amputation level is limited to below the ankle, the longterm survival is better.

Another interesting factor associated survival with borderline significance was the renal function status. A reduced eGFR has been reported to be associated with increased risks of death, cardiovascular events, and hospitalization [28, 29]. Lavery et al. analyzed patients with diabetes who underwent LEA and found that those undergoing dialysis had the worst survival rate, followed by those with CKD and normal kidneys [7]. In the current study, however, the impact of CKD on longterm survival was not as obvious, suggesting that the impact on health of foot gangrene and subsequent LEA outweighed the impact of CKD itself. However, in the patients requiring dialysis, end-stage renal disease still influenced the long-term survival.

This study is limited by the single center and retrospective design. In addition, although we evaluated lower limb circulation, the rate of revascularization was relatively low because of clinical concerns over the risk of kidney injury, intravascular procedure complications in the patients with sepsis, and difficulty of the procedure. Therefore, the revascularization data in this study had little power in survival analysis. Further studies are needed to elucidate the importance of revascularization in patients with infectious foot gangrene.

\section{Conclusions}

The patients with diabetes and amputations caused by infectious foot gangrene in this study had a limited 5years survival rate of around $40 \%$. Age and LEA level were risk factors associated with mortality. The ABI may assist with appropriate decision making with regards to limb amputation level.

\section{Abbreviations}

ABI: Ankle brachial index; aHR: Adjusted hazard ratio; CKD: Chronic kidney disease; eGFR: Estimated glomerular filtration rate; LEA: Lower-extremity amputation; MACE: Major adverse cardiac event; PAD: Peripheral arterial disease

\section{Acknowledgements}

The authors thank the staff and participants of this study for their important contributions.

\section{Funding}

This research was supported by a grant (CMRPG3D0332) from Chang Gung Memorial Hospital to YY Huang. The funders had no role in study design, data collection and analysis, decision to publish, or preparation of the manuscript.

\section{Availability of data and materials}

All clinical data were securely stored in the Chang Gung Memorial Hospital diabetic foot center administrative database. Information on deaths was obtained from the National Health Insurance database.

\section{Authors' contributions}

YY Huang contributed to the conception and design of the study and edited the manuscript. CW Lin contributed to the statistical analysis and wrote the manuscript. HM Yang, SY Hung and IW Chen collected the data and contributed to the discussion. YY Huang gave the final approval of the version to be published. All authors read and approved the final manuscript.

Ethics approval and consent to participate

The Institutional Review Board of Chang Gung Memorial Hospital approved this study (no. 104-1401B).

Consent for publication

Not applicable.

\section{Competing interests}

The authors declare that they have no competing interests.

\section{Publisher's Note}

Springer Nature remains neutral with regard to jurisdictional claims in published maps and institutional affiliations.

Received: 25 July 2017 Accepted: 19 December 2017

Published online: 04 January 2018

\section{References}

1. Faglia E, Clerici G, Clerissi J, Gabrielli L, Losa S, Mantero M, et al. Long-term prognosis of diabetic patients with critical limb ischemia: a populationbased cohort study. Diabetes Care. 2009:32:822-7.

2. MacGill M. Gangrene: causes, symptoms, and treatment. Medical News Today. 2016; http://www.medicalnewstoday.com/articles/158770.php. Accessed 3 Nov 2016

3. American Diabetes Association. Peripheral arterial disease in people with diabetes. Diabetes Care. 2003;26:3333-41.

4. Gemechu FW, Seemant F, Curley CA. Diabetic foot infections. Am Fam Physician. 2013;88:177-84.

5. Tseng $\mathrm{CH}$, Chong CK, Tseng CP, Cheng JC, Wong MK, Tai TY. Mortality, causes of death and associated risk factors in a cohort of diabetic patients after lower-extremity amputation: a 6.5-year follow-up study in Taiwan. Atherosclerosis. 2008:197:111-7.

6. Hambleton IR, Jonnalagadda R, Davis CR, Fraser HS, Chaturvedi N, Hennis AJ. All-cause mortality after diabetes-related amputation in Barbados: a prospective case-control study. Diabetes Care. 2009;32:306-7.

7. Lavery LA, Hunt NA, Ndip A, Lavery DC, Van Houtum W, Boulton AJ. Impact of chronic kidney disease on survival after amputation in individuals with diabetes. Diabetes Care. 2010;33:2365-9.

8. Morbach S, Furchert H, Groblinghoff U, Hoffmeier H, Kersten K, Klauke GT, et al. Long-term prognosis of diabetic foot patients and their limbs: amputation and death over the course of a decade. Diabetes Care. 2012; 35:2021-7.

9. Lin CW, Hsu BR, Tsai JS, Yang HM, Lin JR, Lin CH, et al. Effect of limb preservation status and body mass index on the survival of patients with limb-threatening diabetic foot ulcers. J Diabetes Complicat. 2017:31:180-5.

10. Frykberg RG, Zgonis T, Armstrong DG, Driver VR, Giurini JM, Kravitz SR, et al. Diabetic foot disorders: a clinical practice guideline (2006 revision). J Foot Ankle Surg. 2006;45:S1-S66. 
11. Lin CW, Hsu LA, Chen CC, Yeh JT, Sun JH, Lin CH, et al. C-reactive protein as an outcome predictor for percutaneous transluminal angioplasty in diabetic patients with peripheral arterial disease and infected foot ulcers. Diabetes Res Clin Pract. 2010:90:167-72.

12. Sun JH, Tsai JS, Huang CH, Lin CH, Yang HM, Chan YS, et al. Risk factors for lower extremity amputation in diabetic foot disease categorized by Wagner classification. Diabetes Res Clin Pract. 2012;95:358-63.

13. Rooke TW, Hirsch AT, Misra S, Sidawy AN, Beckman JA, Findeiss LK, et al. 2011 ACCF/AHA Focused Update of the Guideline for the Management of patients with peripheral artery disease (Updating the 2005 Guideline): a report of the American College of Cardiology Foundation/American Heart Association Task Force on practice guidelines. Circulation. 2011;124:2020-45.

14. Izumi Y, Satterfield K, Lee S, Harkless LB, Lavery LA. Mortality of first-time amputees in diabetics: a 10-year observation. Diabetes Res Clin Pract. 2009; 83:126-31.

15. Gok U, Selek O, Selek A, Guduk A, Guner MC. Survival evaluation of the patients with diabetic major lower-extremity amputations. Musculoskelet Surg. 2016;100:145-8.

16. Davies B, Datta D. Mobility outcome following unilateral lower limb amputation. Prosthetics Orthot Int. 2003;27:186-90.

17. Inderbitzi R, Buettiker $M$, Enzler $M$. The long-term mobility and mortality of patients with peripheral arterial disease following bilateral amputation. Eur J Vasc Endovasc Surg. 2003;26:59-64.

18. Pauley T, Devlin M, Heslin K. Falls sustained during inpatient rehabilitation after lower limb amputation: prevalence and predictors. Am J Phys Med Rehabil. 2006:85:521-32. quiz, 533-525

19. Naschitz JE, Lenger R. Why traumatic leg amputees are at increased risk for cardiovascular diseases. QJM. 2008;101:251-9.

20. Gill TM, Allore HG, Holford TR, Guo Z. Hospitalization, restricted activity, and the development of disability among older persons. JAMA. 2004;292:2115-24.

21. Norvell DC, Turner AP, Williams RM, Hakimi KN, Czerniecki JM. Defining successful mobility after lower extremity amputation for complications of peripheral vascular disease and diabetes. J Vasc Surg. 2011;54:412-9.

22. Hung SY, Huang YY, Hsu LA, Chen CC, Yang HM, Sun JH, et al. Treatment for diabetic foot ulcers complicated by major cardiac events. Can J Diabetes. 2015;39:183-7.

23. Driver VR, Fabbi M, Lavery LA, Gibbons $G$. The costs of diabetic foot: the economic case for the limb salvage team. J Vasc Surg. 2010;52:17S-22S.

24. Wukich DK, Raspovic KM, Suder NC. Patients with diabetic foot disease fear major lower-extremity amputation more than death. Foot Ankle Spec 2017: 1938640017694722.

25. Tsai CY, Chu SY, Wen YW, Hsu LA, Chen CC, Peng SH, et al. The value of Doppler waveform analysis in predicting major lower extremity amputation among dialysis patients treated for diabetic foot ulcers. Diabetes Res Clin Pract. 2013;100:181-8.

26. Resnick HE. Relationship of high and low ankle brachial index to all-cause and cardiovascular disease mortality: the strong heart study. Circulation. 2004;109:733-9.

27. O'Hare AM, Katz R, Shlipak MG, Cushman M, Newman AB. Mortality and cardiovascular risk across the ankle-arm index spectrum: results from the cardiovascular health study. Circulation. 2006;113:388-93.

28. Go AS, Chertow GM, Fan D, McCulloch CE, Hsu CY. Chronic kidney disease and the risks of death, cardiovascular events, and hospitalization. N Engl J Med. 2004;351:1296-305.

29. Tonelli M, Wiebe N, Culleton B, House A, Rabbat C, Fok M, et al. Chronic kidney disease and mortality risk: a systematic review. J Am Soc Nephrol. 2006:17:2034-47.

\section{Submit your next manuscript to BioMed Central and we will help you at every step:}

- We accept pre-submission inquiries

- Our selector tool helps you to find the most relevant journal

- We provide round the clock customer support

- Convenient online submission

- Thorough peer review

- Inclusion in PubMed and all major indexing services

- Maximum visibility for your research

Submit your manuscript at www.biomedcentral.com/submit

) Biomed Central 